NBER WORKING PAPER SERIES

\title{
INTERNATIONAL CYCLES
}

\author{
Stephen G. Cecchetti \\ Anil K. Kashyap
}

Working Paper 5310

\section{NATIONAL BUREAU OF ECONOMIC RESEARCH 1050 Massachusetts Avenue \\ Cambridge, MA 02138 \\ October 1995}

Prepared for the International Seminar on Macroeconomics, June 18-20, 1995, Frankfurt, Germany. We thank John Campbell, Bruce Hansen and Pete Klenow for helpful conversations, seminar participants at the Federal Reserve Banks of Chicago and Philadelphia and the Osaka Econometrics Conference and our discussants Paul Sobderlind and James Stock for their comments. Burt Porter provided excellent research assistance. We thank the University of Chicago Graduate School of Business Faculty Research Fund, National Science Foundation and the Federal Reserve Banks of Chicago and Cleveland for research support. We alone are responsible for all opinions and any errors in this paper. This paper is part of NBER's research program in Monetary Economics. Any opinions expressed are those of the authors and not those of the National Bureau of Economic Research.

(C) 1995 by Stephen G. Cecchetti and Anil K. Kashyap. All rights reserved. Short sections of text, not to exceed two paragraphs, may be quoted without explicit permission provided that full credit, including (c) notice, is given to the source. 


\title{
INTERNATIONAL CYCLES
}

\begin{abstract}
We study twenty years of monthly production data for 11 manufacturing industries in 19 countries. Using the fact that in some countries production virtually shuts down for one summer month, together with the differences in the timing of aggregate cyclical fluctuations, we are able to learn about the cost structure of different industries. Our primary finding is that during a boom year summer shut-downs are shorter. Rather than increasing production further during the rest of the year, producers reallocate activity from high output months to low output months.

We also find that there are important seasonal/cyclical interactions common to all industries within a given country, and that these countries effects are larger than the pure industry effects. The correlation of the cross-country differences with measures of taxation and labor market structure suggests the possibility that differences in the willingness (and ability) to substitute labor intertemporally are responsible for the variation.
\end{abstract}

Stephen G. Cecchetti

Department of Economics

The Ohio State University

410 Arps Hall

1945 North High Street

Columbus, OH 43210-1172

and NBER
Anil K. Kashyap

Graduate School of Business University of Chicago 1101 East 58th Street

Chicago, IL 60637 and NBER 


\section{Introduction}

While most economists are aware that production patterns around the world are tremendously seasonal, the differences in the degree of seasonality across countries has attracted very little attention.' Figure 1 plots seasonally unadjusted industrial production in manufacturing for the U.S., Germany, Sweden and Italy. Even though our later estimates will show that over $75 \%$ of the variability of the growth of U.S. production can be explained by seasonal swings, the figure reveals that the seasonality in the U.S. pales in comparison to countries like Italy and Sweden, where production virtually shuts down for one month during the summer.

The same sort of comparison can be done using indicators of the business cycle across countries. Figure 2 plots a detrended and seasonally adjusted version of the same series. While one can see clear similarities in these business cycle measures, there are also important differences. For instance, at the beginning of this decade, as the U.S. was slipping into a recession, German production, presumably because of a burst of activity associated with unification, was booming.

Together the pictures imply that at times one country's economy is booming, while another's is slumping and more importantly, there are long spells every year where some countries have huge amounts of capital that are lying idle. Our goal in this paper is to exploit this variation to learn about the cost structure of different countries and industries.

The intuition underlying our analysis is simple. Consider a country like France, where

\footnotetext{
${ }^{1}$ Notable exception are Beaulieu and Miron (1992) and Beaulieu, Mackie-Mason and Miron (1992). See also Miron (1990) and Ghysels (1991).
} 
Figure 1: Total Manufacturing, Not Seasonally Adjusted Selected Countries, in logs
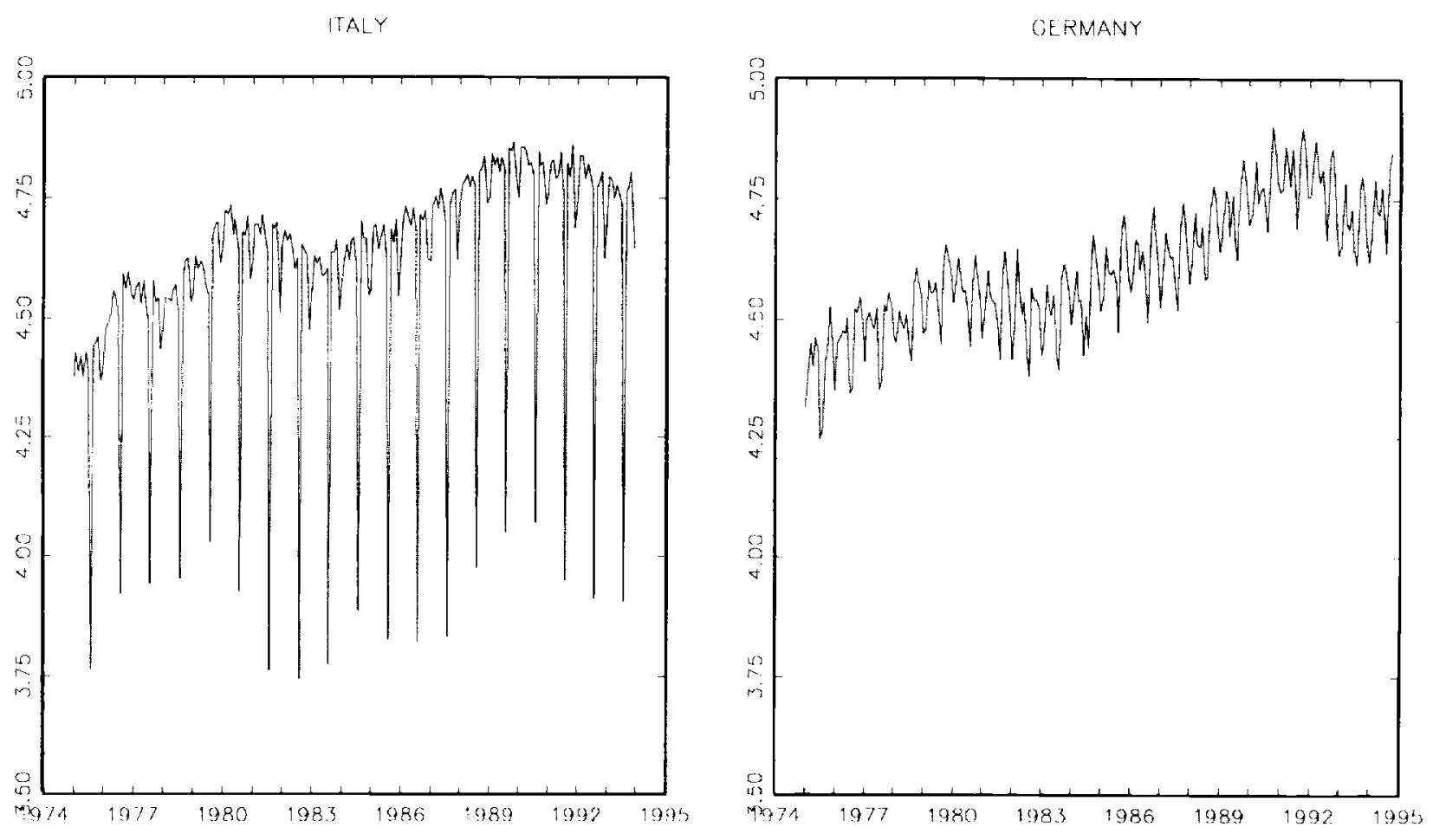

SWEDEN
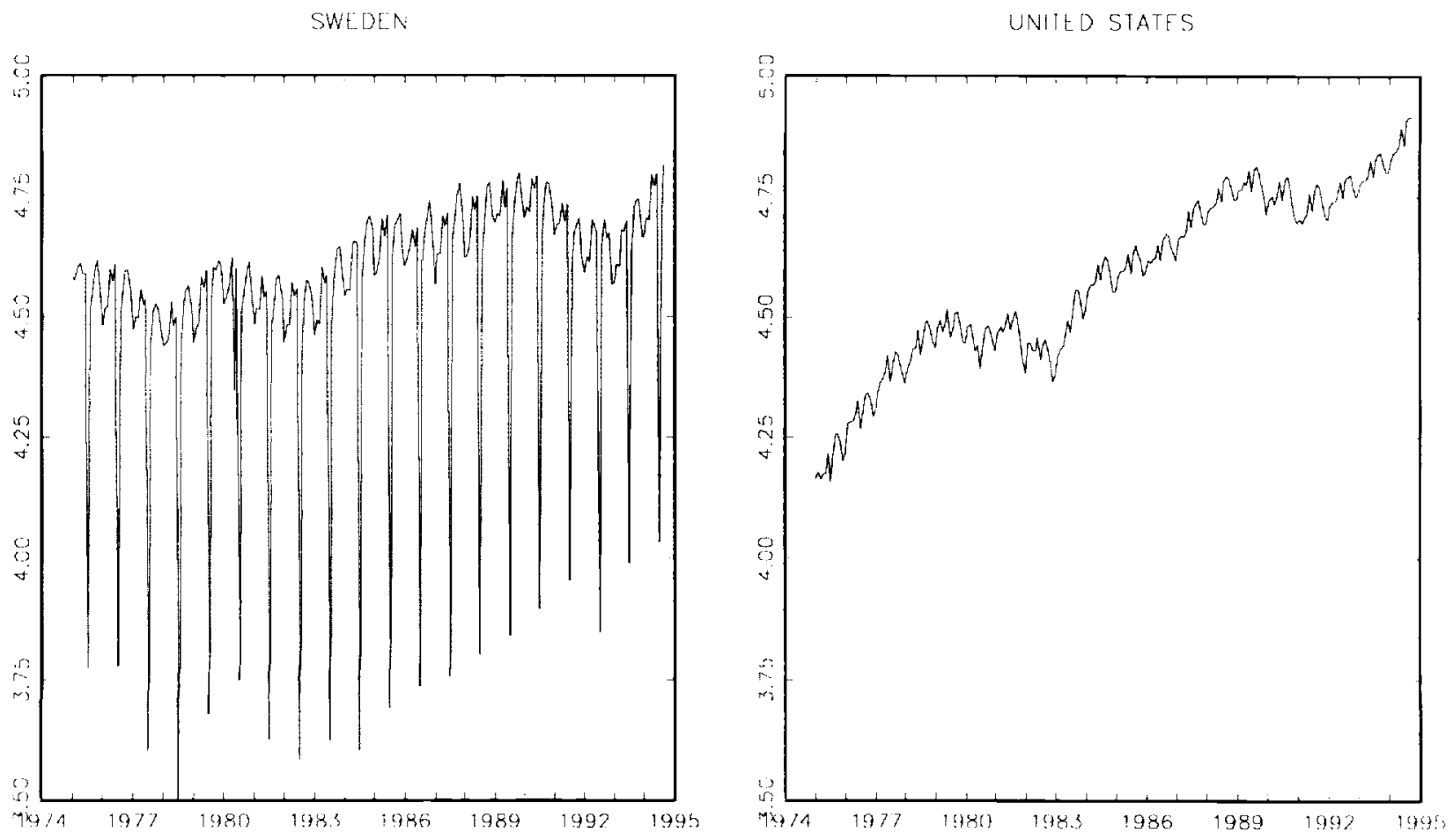
Figure 2: Band-Pass Filtered Business Cycle Proxy Selected Countries
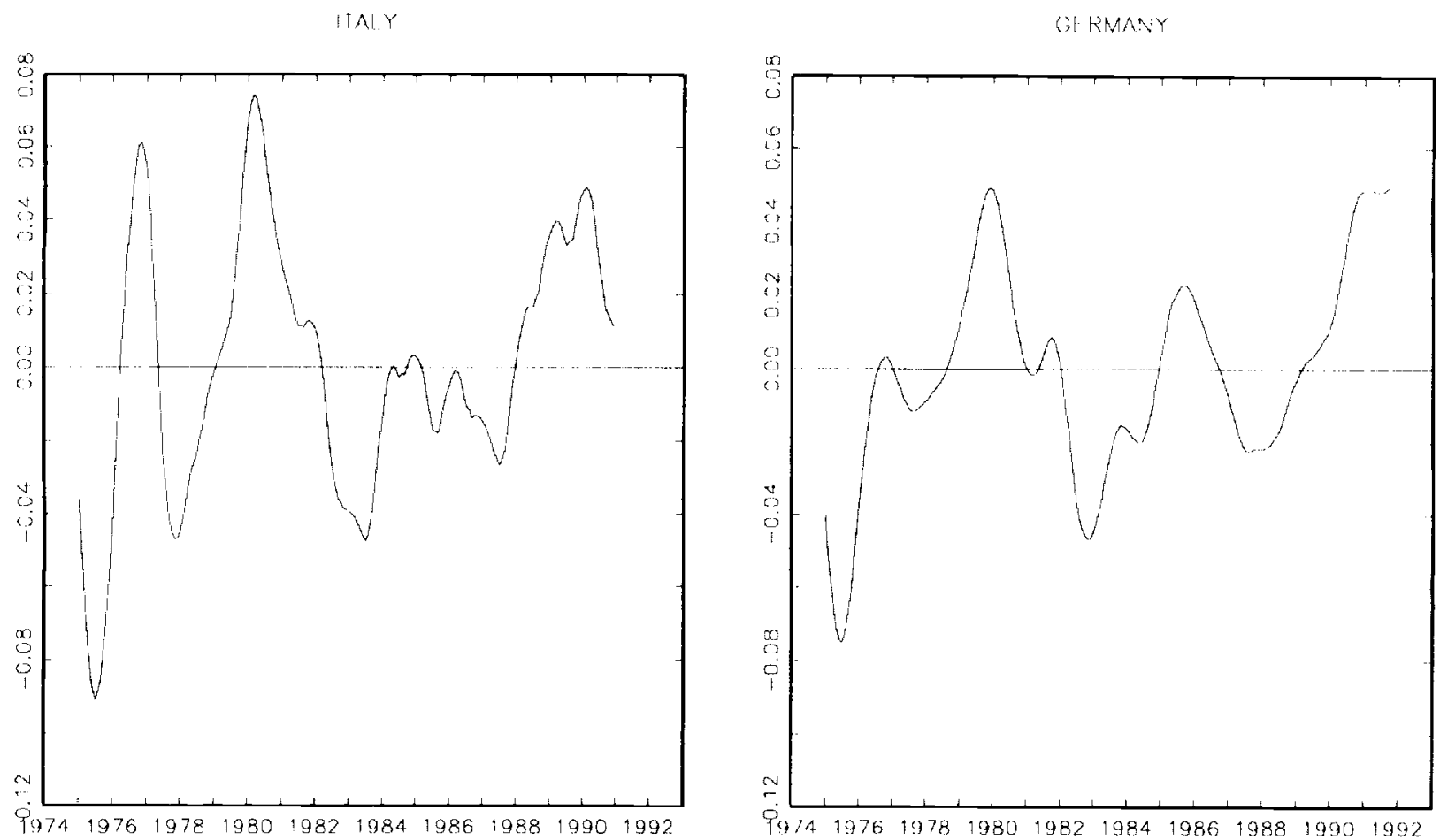

SWION
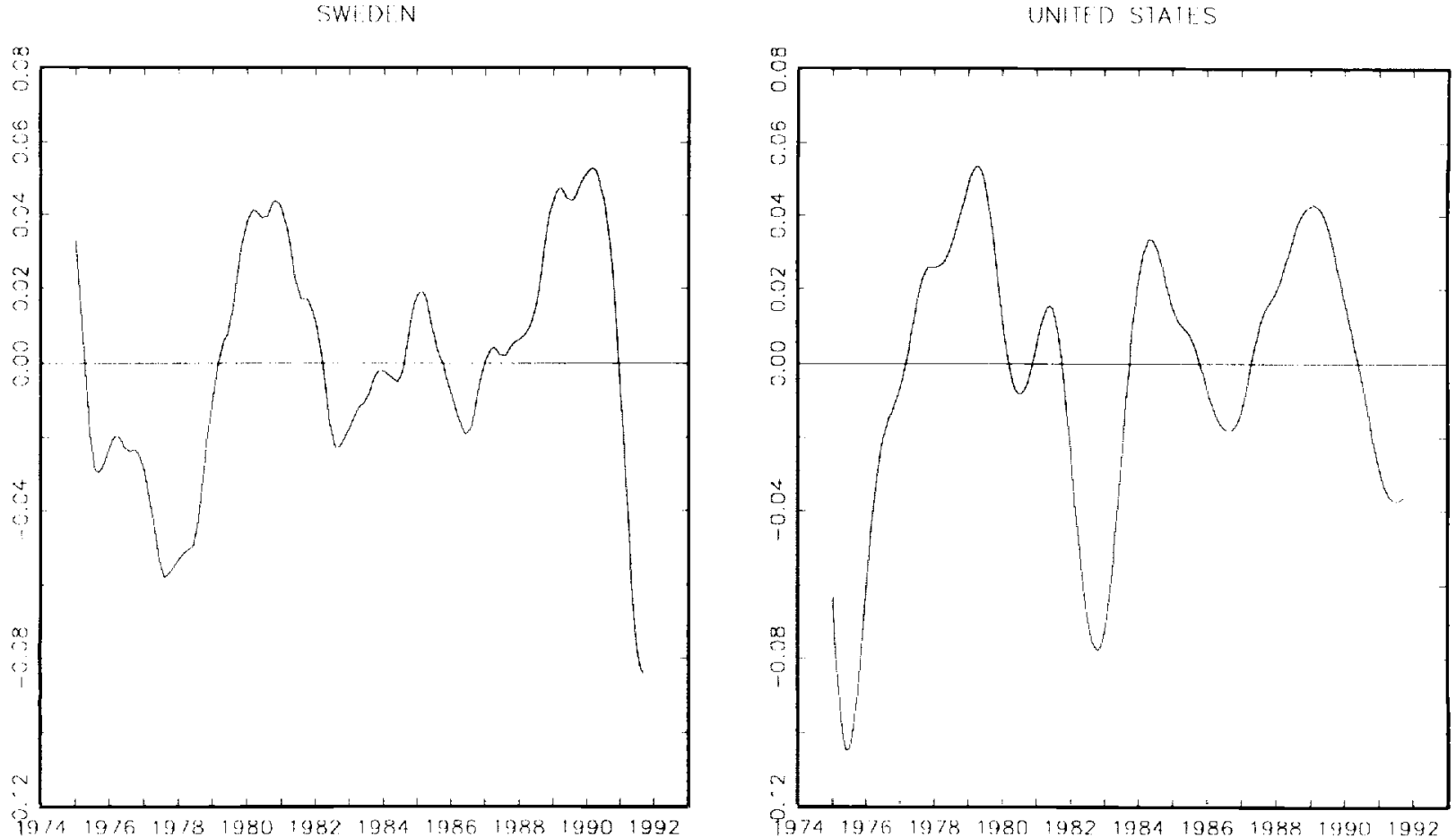
every August production typically grinds to a halt. If capacity constraints are important, then during a boom year it will be efficient to shorten the August holiday rather than trying to increase produce further during the rest of the year. Thus, by looking at whether the seasonal cycle in production changes over the course of the business cycle, we can make inferences about firms' cost curves.

To formalize this intuition we develop a two-period model of the production scheduling problem facing a firm. The model shows how changes in seasonal production patterns over the course of the business cycle are related to the shape of firms cost curves. The main point of the model is to demonstrate that seasonal and cyclical interactions will not occur when firms' marginal cost of producing is a linear function of output.

Intuition for why the linearity of marginal cost rules out connections between seasonal cycles and business cycles is straightforward: If the attractiveness of producing in a high season relative to a low season does not change during a business cycle expansion, then seasonal production plans will not depend on the stage of the business cycle. Loosely speaking, if marginal costs are a linear function of output, then a boom does not change the relative cost of producing in different seasons. With non-linear costs, cyclical expansions do change the relative costs of producing across seasons.

This logic contrasts sharply with the reasoning in most of the literature that looks at seasonal adjustment. There, the central question is whether business cycles and seasonal cycles can be mechanically decomposed. This has led to a detailed exploration of the deficiencies in the X-11 seasonal adjustment procedure -- see, for example, the survey in U.S. Department of Commerce (1978). But, these criticisms are typically made on statistical 
grounds and do not involve the use of a model to show that optimization on the part of firms leads to a necessary connection between business cycles and seasonal cycles. ${ }^{2}$ Aside from Cecchetti, Kashyap and Wilcox (1995), who conduct a similar exercise using U.S. data, the only other paper similar to ours is Beaulieu, Mackie-Mason and Miron (1992). ${ }^{3}$ Beaulieu et al measure the extent to which the size of business cycles and seasonal cycles are related across countries, and find that countries with large seasonal cycles also have large nonseasonal fluctuations. They also provide an example showing how the presence of capacity constraints can connect seasonal cycles and business cycles. We view their work and ours as complementary, with the primary difference being that we provide both a more complete model that can be used to catalog our results and a new set of facts about the changing nature of the seasonal cycle over the course of the business cycle.

To preview the results, we find that seasonal fluctuations in all 19 countries we study are quite large, but are often not highly correlated with each other. Our estimates of country specific measures of the business cycle also are not highly correlated. For 8 of the 11 twodigit manufacturing industries in our sample, there are important interactions between the size of the seasonal cycle and the state of the business cycle. In each of these cases, the seasonality in production shrinks considerably during a boom, suggesting that capacity

${ }^{2}$ Christiano and Todd (1995) provide a counter-example by describing a fully specified model for which this decomposition does not cause problems. But since their model excludes costs of adjusting short-run capacity it eliminates the channel that we emphasize. Hansen and Sargent (1993) also provide some example economies where no interaction occurs. We discuss their results in the next section.

${ }^{3}$ Stockman (1988) looks at differences in seasonality across industries and countries and finds significant common patterns in both. However, he does not look at interactions between seasonal cycles and business cycles. 
constraints are important. However, there are also seasonal/cyclical interactions that are common to all industries in a given country, and these country effects are typically much larger than the pure industry effects.

The organization of the paper is as follows. We begin with a brief discussion of the model. Then, in section 3 , we document a number of facts about the commonality of business cycles and seasonal cycles across countries and industries. In section 4 , we interpret the results along the lines suggested by the model. Using panel data on the degree of interaction between seasonal cycles and business cycles, we recover estimates of the importance of industry-level and country-level fixed-effects in the interaction. Section 5 reports our conclusions.

\section{Modeling Seasonal and Cyclical Interactions}

\section{A A Simple Model}

The model we propose is a simple multi-country generalization of Cecchetti, Kashyap and Wilcox's (1995) model of the interaction between business cycles and seasonal cycles. ${ }^{4}$

Both models rely on two key assumptions that make interactions possible. First, we require that any cyclical influence on demand and/or cost persists across seasons, i.e, that the business cycle be longer than the seasonal cycle. Without this condition, news about the strength of the business cycle will not lead firms to reorganize their seasonal pattern of production. Second, we assume that commitment is a sufficiently important feature of firms' production scheduling decisions that seasonal capacity cannot easily be added and subtracted.

\footnotetext{
${ }^{4}$ The motivation for this approach is given in Rotemberg and Woodford (1993).
} 
Absent some element of commitment, cyclical swings could be accommodated purely by adjusting capacity, leaving no scope for seasonal and cyclical interactions. ${ }^{5}$ Together, these two assumptions mean that firms will occasionally find themselves with too little or too much capacity given the current state of the business cycle, so that it may be advantageous to alter the recurring seasonal changes in production in response to the state of the business cycle.

To keep things manageable, we make a number of simplifying assumptions. First, we assume that there are two seasons (denoted by S) in each year and that during the year the state of the business cycle (measured by $\lambda$ ) is fixed. Furthermore, firms' capacity is fixed during the year. Within this context we examine the cost minimization problem that firms producing in industry $i$ and located in country $j$ will face. Assuming that all firms are identical within a given industry, the problem can be written as:

$$
\min _{Q_{i j, t}} \sum_{t=1}^{2} C\left(Q_{i j, t} ; S_{t}, \lambda_{j}\right)+h\left(I_{i j, t-1}\right)
$$

subject to $I_{i, j, t}=I_{i, j, t-1}+Q_{i j, t}-X_{i, j, t}$ (with $I_{i, j, 0}$ and $I_{i, j, 2}$ given), where I denotes inventories, $\mathrm{Q}$ denotes production, $\mathrm{X}$ denotes sales, $\mathrm{C}$ describes the cost function and $\mathrm{h}$ describes the cost of holding inventories -- to reduce notational clutter, we

\footnotetext{
${ }^{5}$ As Braun and Evans (1994) emphasize, the propagation of seasonal shifts to longer horizons crucially depends on the nature of the adjustment costs of capital. Thus, we conjecture that the theoretical examples by Christiano and Todd (1995) which suggest that seasonal cycles and business cycles do not interact are driven by the fact that there are no adjustment costs for capital in their examples. Hansen and Sargent (1993) examine some theoretical examples that include adjustment costs, but we suspect that there is not enough persistence in their shocks to generate spillovers.
} 
suppress the $\mathrm{i}$ and $\mathrm{j}$ subscripts on $\mathrm{C}$ and $\mathrm{h}$. To allow for the possibility that the technology gives firms an incentive to bunch production, we permit the marginal cost curve to become steeper or flatter as output expands: $\mathrm{C}_{\mathrm{QQ}} \geq 0$, but $\mathrm{C}_{\mathrm{QQQ}}$ can be positive or negative. We also make standard assumptions about the storage cost function, so that we require $h^{\prime} \geq 0$ for $I \geq$ $0, h^{\prime}<0$, for $\mathrm{I}<0$ and $h(0)=0$. If inventories are negative this means that the firms have run out of goods and had to backlog orders, which we assume is costly.

By allowing for backlogging, we can, without loss of generality, normalize the two seasons, call them 1 and 2 , so that season 2 is the high output season: $Q_{i, j, 2}>Q_{i, j, 1}--$ we ignore discounting across the two periods. Similarly, we define $\lambda_{j}$ to be a positive measure of the business cycle so that $\mathrm{dQ}_{\mathrm{i}, \mathrm{,}, \mathrm{I}} / \mathrm{d} \lambda_{\mathrm{j}}>0$. Our previous assumption about the persistence of the business cycle implies that we can examine adjacent periods setting $\lambda_{\mathrm{j}, \mathrm{t}} \approx \lambda_{\mathrm{j}, \mathrm{t}+1}=\lambda_{\mathrm{j}}$.

Given this setup, the usual optimality condition for inventory holding requires that producing now and storing the output is no cheaper than delaying the production for one period. Formally, this first order condition can be written as:

$$
C_{Q}\left(X_{i, j, 1}+I_{i, j, 1} ; S_{1}, \lambda_{j}\right)-C_{Q}\left(X_{i, j, 2}-I_{i, j, 1} ; S_{2}, \lambda_{j}\right)+h^{\prime}\left(I_{i, j, 1}\right)=0
$$

It will be convenient to work with the continuous time approximation to this expression. Taking the limit as the seasons become arbitrarily close together and suppressing some notation we obtain:

$$
\mathrm{C}_{\mathrm{QQ}} \mathrm{Q}_{\mathrm{S}}+\mathrm{C}_{\mathrm{QS}}=\mathrm{h}^{\prime}(\mathrm{I})
$$

To deduce the connection between changes in the seasonal production patterns over 
the course of the business cycle and the curvature of the cost function, we need to totally differentiate this equation with respect to $\lambda$. Doing so implies that:

$$
Q_{S \lambda}=\frac{h^{\prime \prime} I_{\lambda}-C_{Q S \lambda}-C_{Q Q S}-Q_{S}\left(C_{Q Q Q} Q_{\lambda}+C_{Q Q \lambda}\right)}{C_{Q Q}}
$$

The result tells us that the seasonality in production depends on the stage of the business cycle if either the marginal cost of producing is a non-linear function of output or the cost of storing goods is a non-linear function of the amount being stored. The intuition for this result is straightforward. If the third derivative of the cost function is non-zero, then as output expands the marginal cost curve becomes either steeper or flatter and the attractiveness of producing in the high season relative to the low season changes, so that production will be reallocated between the seasons. Alternatively, if $h$ " is non-zero (and presumably positive), then additional storage is increasingly costly, and again it becomes efficient to reorganize the timing of production, possibly paying additional production costs rather than building up too high a level of inventories.

\section{B Identification and Interpretation}

Given these two possible explanations for a seasonal and cyclical interaction, identifying its source requires either some additional information or further assumptions. ${ }^{6}$ One solution to the identification problem is to assume that the cost of holding inventories is

\footnotetext{
${ }^{6}$ We have chosen to resolve the identification problem without trying to directly estimate the cost function because of the many problems in doing so -- see Burnside, Eichenbaum and Rebelo (1995) and the associated comments for a recent summary of the relevant issues.
} 
a linear function of the level of inventories -- i.e., h" $=0{ }^{7}$ Evidence regarding trade credit financing provides one justification for this assumption. If interest costs are the primary component of the holding costs, then setting h" $=0$ amounts to assuming that the interest rate charged on a loan used to finance inventories is constant (regardless of the loan size). This is consistent with Petersen and Rajan's (1994) finding that there is little variation in the terms under which trade credit is extended. They show that if a firm can borrow using trade credit, then the financing costs rarely depend on that firm's characteristics -- instead the costs for different firms in an industry are fairly uniform. Thus, one might conclude that interest cost is an approximately linear function of the size of inventories being financed. ${ }^{8}$

Beyond this, some indirect empirical evidence on the shape of the holding cost function is available from Cecchetti, Kashyap and Wilcox (1995). They find that for 14 of 20 two-digit industries in the United States, seasonal inventory patterns do not change over the course of the business cycle. Thus, their estimates suggest that $\mathrm{I}_{\lambda}$ is zero.

Together these considerations imply that, as a benchmark, it is plausible to eliminate the inventory holding cost term from equation (4). If this is done, any changes in the pattern of seasonality over the course of the business cycle mist come solely from the curvature of the marginal cost function. More specifically, this identifying assumption tells us that if the seasonal cycle shrinks over the course of the business cycle, then the marginal cost curve

\footnotetext{
${ }^{7}$ Assuming h" $=0$, restricts the cost function. For instance, if we insist that production occurs in all seasons then it is not possible to satisfy the second order conditions if $\mathrm{C}_{\mathrm{QQ}}<0$, i.e. if there are increasing returns to scale. See Cecchetti, Kashyap and Wilcox (1995) for an extended discussion of these issues.

${ }^{8}$ The trade credit results may be one reason why attempts to link inventory decisions to real interest rates have been so disappointing (Blinder and Maccini (1991)).
} 
must be getting steeper as output expands -- $\mathrm{C}_{\mathrm{QQQ}}$ or $\mathrm{C}_{\mathrm{QQ \lambda}}$ or $\mathrm{C}_{\mathrm{QQS}}$ or $\mathrm{C}_{\mathrm{QS \lambda}}>0$.

Conversely, if the seasonal cycle is becoming larger during a boom, firms must be bunching their production into the normally high output seasons during a boom. This sort of behavior makes sense if the marginal cost curve is flattening out as output expands. Thus, we can determine the importance of capacity constraints by looking at whether, and if so how, the seasonal cycle changes over the course of the business cycle.

The panel data set we use allows us to do more than just measure $Q_{s \lambda}$ in each of the industries in each country. We can take the panel of estimates and regress them on a set of country and industry dummy variables to determine the size of the country and industry fixedeffects. Given our identifying assumption, this regression will tell us what fraction of the curvature of the cost function comes from country specific factors and what part comes from aspects of the industry's technology that is constant across countries. For example, the coefficient on Finland in the fixed-effects regression measures the extent to which all Finnish industries exhibit a common change in the degree of seasonality in a boom. Any shrinkage or expansions reflects country-specific differences such as preferences regarding intertemporal labor supply patterns.

Similarly, the coefficients on the industry variables in the regression will measure the extent to which industry cost functions have a similarity in their curvature. Thus, the coefficient for the metal products industry shows how much the change in the seasonality is due to swings in efficiency that are shared by all metal products manufacturers. In this case, any shrinkage or expansion would reflect the basic technological features of the common, industry-wide production process. 
The preceding discussion appears to ignore any role that demand variation might play connecting seasonal cycles and business cycles. In fact, demand considerations are being captured through the inventory holding term in equation (4). To see why, notice that a demand-based explanation for the interactions would depend on the marginal revenue from selling goods in different seasons varying with the state of the business cycle. If these fluctuations in marginal revenue were present, then the return to holding goods in inventory would also vary, leading firms to adjust their seasonal pattern of inventory accumulation differently over the course of the business cycle. Thus, there is a deep connection between demand-based explanation for seasonal and cyclical interactions and inventory movements.

Linear holding costs turns out to be the knife-edge case which rules out demand based explanations. The intuition for why this is so begins with the recognition that if holding costs are linear then there is a constant marginal cost of moving a unit that is ready to be sold from one period to another. Then, even if marginal revenue of selling in the high season relative to the low season were to vary with the state of the business cycle, firms would keep adjusting inventories to force this marginal revenue gap to come back to the constant cost they pay for storing finished goods. Demand fluctuations can only give rise to seasonal and cyclical interactions if the holding cost function is non-linear.

The fact that holding costs may be non-linear gives rise to the possibility that demand variation is contributing to seasonal and cyclical interactions. The panel dimension of our data permits us to make an alternative set of identifying assumptions that include a role for demand factors. It seems plausible to assume that the curvature of the cost function within an industry is the same across countries. This, together with the symmetric assumption that 
within-country variation across industries comes from primarily from differences in demand, means that we can use the results from the fixed-effects regressions to recover estimates of the importance of both demand and cost considerations. More precisely, under these identifying assumptions, shifts in demand can be responsible for changes in seasonality over the course of the business cycle that are shared by all industries within a country.

Furthermore, cross-country comparisons of the same industry yield information on production costs.

Using these restrictions, the coefficient on Finland in our fixed-effects regressions provides an estimate of the importance of Finnish demand shifts in altering the seasonality of production. Conversely, the coefficient for the metal products industry tells us how much of the change in seasonality for this industry is driven by the technological characteristics of this industry. This reasoning suggests comparing the magnitude of the industry and country coefficients to get a sense of the relative importance of demand and cost shifts.

Of course, the two approaches to identification have some similarities. Under either set of assumptions, the coefficients on the industry variables provide information about the importance of industry cost conditions. The country coefficients can be interpreted as measuring either local demand or cost conditions. Thus, loosely speaking, cross-country differences in the size of the summer slowdown are either imputed to differences in the willingness to supply labor or differences in the seasonal demand for manufactured goods. That this sort of ambiguity is present is not very surprising. ${ }^{9}$

${ }^{9}$ Another more appealing alternative to identification would be to use additional information. Cecchetti, Kashyap and Wilcox (1995) show how inventory data can be used to gauge the importance of demand effects in causing seasonal and cyclical interactions. Unfortunately, 


\section{Basic Facts about International Cycles}

The production data that we analyze comes from the Organization of Economic Cooperation and Development (OECD) "Indicators of Industrial Activity". We study 11 industries from 19 of the OECD countries. The rules we use to verify the integrity of the series are described in the appendix. Most series are available starting in 1975 and going through 1994.

Studying the interaction of the business cycle and the seasonal cycle, requires construction of a business cycle indicator. We follow the suggestion of Baxter and King (1995), who recommend a band-pass filtering procedure that can be used to mechanically construct the business cycle component of any time series. The Baxter-King procedure, as we have implemented it, removes all fluctuations in a series that are shorter than 18 months or longer than 8 years. ${ }^{10}$ The logarithm of total manufacturing output in each country was filtered to construct our business cycle proxies. Given this convention, production can be decomposed into its seasonal, cyclical and other components:

$$
\mathrm{y}_{\mathrm{j}, \mathrm{t}}=\bar{y}_{\mathrm{j}, \mathrm{t}}+\mathrm{S}_{\mathrm{j}, \mathrm{t}}+\mathrm{x}_{\mathrm{j}, \mathrm{v}}
$$

where $y_{j, t}$ is the $\log$ of industrial production in country $j$ at time $t, \bar{y}_{j, t}$ is the cyclical component of production at that time for that country (calculated using the band-pass filter), $\mathrm{S}_{\mathrm{j}, \mathrm{t}}$ is the seasonal component of production and $\mathrm{x}_{\mathrm{j}, \mathrm{t}}$ is the remaining random component of

comparable inventory data are not available for the vast majority of the industries and countries that we study.

10 To avoid losing the 1974/75 recession, we collected an additional 3 years worth of aggregate industrial production data, so that the cyclical indicators are available from the beginning of 1974 onward. 
production. (For the data pertaining to the OECD as a whole we drop the $\mathrm{j}$ subscript.)

Before looking into the subtleties of how the seasonal cycle and business cycle might interact, we report some basic facts about the seasonal and business cycles. As we note below, a number of stylized facts about the size and correlations among seasonal cycles and business cycles have been previously chronicled. However, because these observations have been made across a series of papers, using a range of statistical techniques, and been based on a variety of data sets, we believe that it is important to begin by documenting the basic facts using our data and filtering techniques.

Table 1 provides summary measures on the differences in seasonality across countries. The first column, which reports the standard deviation of the first-difference of the logarithm of industrial production in each of the countries, reinforces the conclusion from Figure 1 that there is a tremendous difference in the total variability of production across countries. For instance, the standard deviation of 0.358 for Italy implies that a ninety-five-percent confidence interval would allow for a seventy-percent swing in monthly production!

The next column reports the $\mathrm{R}^{2}$ from regressing the first difference of (the $\log$ of) industrial production on a set of 12 seasonal dummies. As Beaulieu and Miron (1992) have emphasized upwards of seventy percent of the output fluctuations in every OECD country are seasonal. ${ }^{11}$ Nevertheless, there are striking differences in the degree of deterministic

${ }^{11}$ Beaulieu and Miron do a similar calculation (comparing the standard deviation of their seasonal coefficient estimates and residuals) for monthly retail sales in 20 OECD countries and real GDP in 14 countries. The seasonality in sales and production across countries is fairly similar, however, their estimates of the seasonality in GDP do not line up as closely with their estimates of the seasonality in production. For instance, Japan is estimated to have the second most seasonal variation in GDP even though Japanese production shows relatively little seasonal variation. Nevertheless, the general proposition that seasonality is the dominant source of 
Table 1: Descriptive Statistics for the Growth Rate of Aggregatc Industrial Production

\begin{tabular}{||l|c|c|c|c||}
\hline \hline & $\begin{array}{c}\text { St. Dev. } \\
\text { of Growth } \\
\text { Rate }\end{array}$ & $\begin{array}{c}\text { Fraction of } \\
\text { Variance due to } \\
\text { Deterministic } \\
\text { Seasonality }\end{array}$ & \multicolumn{2}{|c||}{$\begin{array}{c}\text { Correlation of } \\
\text { Country } \\
\text { with total OECD } \\
\text { (Monthly) }\end{array}$} \\
(Quarterly) \\
\hline OECD Total & 0.060 & 0.97 & 1.00 & 1.00 \\
Austria & 0.095 & 0.87 & 0.74 & 0.97 \\
Belgium & 0.137 & 0.90 & 0.35 & 0.90 \\
Canada & 0.089 & 0.96 & 0.57 & 0.81 \\
Denmark & 0.188 & 0.90 & 0.13 & 0.96 \\
Finland & 0.218 & 0.96 & 0.05 & 0.98 \\
France & 0.167 & 0.97 & 0.90 & 0.91 \\
Germany & 0.077 & 0.80 & 0.94 & 0.95 \\
Grece & 0.083 & 0.73 & 0.91 & 0.47 \\
Ireland & 0.101 & 0.83 & 0.98 & 0.96 \\
Italy & 0.358 & 0.97 & 0.85 & 0.91 \\
Japan & 0.071 & 0.93 & 0.71 & 0.67 \\
Luxcmbourg & 0.138 & 0.87 & 0.90 & 0.91 \\
Netherlands & 0.082 & 0.82 & 0.64 & 1.00 \\
Norway & 0.257 & 0.94 & 0.09 & 0.84 \\
Portugal & 0.171 & 0.94 & 0.87 & 0.93 \\
Spain & 0.256 & 0.95 & 0.85 & 0.96 \\
Sweden & 0.357 & 0.98 & 0.02 & 0.99 \\
U.K. & 0.086 & 0.87 & 0.86 & 0.79 \\
U.S. & 0.053 & 0.76 & 0.07 & 0.04 \\
\hline \hline
\end{tabular}

First column is the standard deviation of the change in the log of the monthly total manufacturing production data (ISIC 3000) for each country, and the OECD total. The second column is the $R^{2}$ of the seasonal regression of the growth rate on twelve seasonal dummy variables. The final column is the correlation of the fitted value of each countries seasonal regression with the fitted value of the from the OECD total seasonal regression. 
seasonality across countries. Together the first two columns of Table 1 suggest that the U.S. has relatively small amounts of both overall and seasonal volatility. Conversely, many of the European countries (e.g. Italy or Sweden) have fluctuations that are not only four or five times bigger than the U.S., but also are almost wholly accounted for by seasonal shifts.

This contrast leads us to wonder to what extent are the seasonal fluctuations across countries common? Comparison of the coefficients on the seasonal dummy variables in the previously mentioned regression for the entire OECD to the coefficients for each country allows us to answer this question. The correlation between the pairs of the twelve coefficients are shown in column 3 of the table -- i.e. the correlation of the estimated values of $S_{1}$ and $S_{j, r}$ The monthly comparison may be misleading since, as Beaulieu and Miron emphasize, the dominant pattern for most countries includes a large summer slowdown that occurs in either July or August . This concern is addressed by shifting to quarterly data. Column 4 of the table shows that with this change many countries line up the aggregate OECD pattern.

Nevertheless, the correlations for Japan and the U.S. also demonstrate that even in quarterly data there are important differences in the precise seasonal patterns across countries. For instance, with the quarterly data all pairwise comparisons between the sets of seasonal coefficients for the U.K., U.S., Germany and Japan indicate significant differences. Thus, we conclude that the seasonal production patterns are substantially dissimilar.

Stockman (1988) has noted that both industry and country patterns of seasonality can be important. To put our country-level results in perspective, we regressed the standard

variation in the data is strongly confirmed by their work. 
deviation of the first difference of (the log of) output (in each industry and each country) on a set of industry and country dummy variables. ${ }^{12}$ By constraining the coefficients on the country and industry dummies to sum to zero, these effects automatically net out, and the size of the effects can be gauged by comparing the magnitude of the coefficients.

Table 2 shows that the largest estimated effects are attributable to swings that are common to all industries within a country, rather than to differences across countries within any given industry. For instance, the most volatile industry-level production pattern is in the transportation equipment industry. Yet, the reduction in volatility that is common to all industries in Japan or the US is almost 50 percent bigger than the added variability associated with production in the transportation equipment industry. A summary measure of the relative importance of the country and industry effects is the mean absolute value of the estimated country and industry coefficients. We were surprised to learn that the country effects are roughly twice the size of the industry effects.

Tables 1 and 2 lead us to draw three main conclusions. First, as is well known, a tremendous amount of volatility in production is accounted for by seasonal shifts. Second, the seasonal shifts that take place are not always highly correlated across countries. Third, the country-level differences in seasonality are larger than the industry-level patterns in seasonality. Collectively, these findings suggest that the extent of unused capacity varies significantly across countries.

12 The regressions were run using weighted least squares, with the weights reflecting the output share of industry $i$, in country $j$, relative to total OECD output. This weighting scheme guarantees that small industries or countries that are especially volatile do not dominate the results. However, the results are not sensitive to the use of weights. 
Table 2: Decomposition of Volatility in Growth that is due to Country and Industry Fixed Effects

\begin{tabular}{||l|c|c||}
\hline \hline Country or Industry & $\begin{array}{c}\text { Deviation } \\
\text { from Meanl }\end{array}$ & $\begin{array}{c}\text { p-value } \\
\text { for } H_{o}: \beta=0\end{array}$ \\
\hline Food & -0.074 & 0.00 \\
Textiles & 0.023 & 0.32 \\
Wood and Wood Products & 0.020 & 0.50 \\
Paper, Printing and Pub. & -0.059 & 0.00 \\
Chemicals & -0.059 & 0.00 \\
Non-Metallic Mineral Prod. & -0.030 & 0.05 \\
Basic Metals & 0.001 & 0.97 \\
Metal Products & 0.022 & 0.03 \\
Nonelectrical Machinery & 0.046 & 0.00 \\
Electrical Machinery & 0.024 & 0.13 \\
Transportation Equipment & 0.086 & 0.00 \\
\hline Anstria & -0.077 & 0.00 \\
Belgium & -0.047 & 0.00 \\
Caniada & -0.098 & 0.00 \\
Deninark & 0.040 & 0.03 \\
Finland & 0.070 & 0.06 \\
France & 0.043 & 0.31 \\
Germany & -0.094 & 0.00 \\
Greece & 0.000 & 0.99 \\
Ircland & -0.040 & 0.01 \\
Italy & 0.188 & 0.00 \\
Japan & -0.131 & 0.00 \\
Luxembourg & -0.005 & 0.83 \\
Netherlands & -0.081 & 0.00 \\
Norway & 0.077 & 0.00 \\
Portugal & 0.070 & 0.06 \\
Spain & 0.110 & 0.01 \\
Sweden & 0.206 & 0.00 \\
U.K. & -0.101 & 0.00 \\
U.S. & -0.129 & 0.00 \\
\hline Mean of the Data & 0.2054 & 0.00 \\
\hline Mean Absolute Value of Industry Effects $=0.050$ \\
Mean Absolute Value of Country Effects $=0.102$ \\
\hline \hline
\end{tabular}

Results from weighted-least-squares regression of the standard deviation of production growth in the 209 industry/country combinations on industry and country dummy variables, weighted by the inverse of the share of industry $i$, in country $j$, relative to total OECD production. The coefficients of the industry and country effects are each constrained to sum to zero individually. Hypothesis test results are based on standard errors that are robust to heteroskedasticity. 
Our last set of descriptive statistics, reported in Table 3, provide information about the Baxter-King business cycle proxies, $\bar{y}_{\mathrm{j}, \iota^{\circ}}$ The first column shows the standard deviation of $\overline{\mathrm{y}}_{\mathrm{j}, \mathrm{v}}$. This measure of volatility suggests that cyclical fluctuations in Japan and the U.S. are roughly twice the size of fluctuations in several of the smaller OECD economies, including Norway, Greece and the Netherlands -- Backus and Kehoe (1992) confirm that large differences of this sort are present in longer times-series. The next five columns of the table report the cross-correlations of our business cycle proxies with the cyclical component of total OECD production. Like Stockman (1988), we find that the contemporaneous correlations, especially for the largest countries, tend to be quite high. However, the correlations at different lags vary noticeably, so that loosely speaking, the US business cycle tends to lead the aggregate OECD cycle, while the German cycle lags it. Among the smaller countries, e.g. Norway or Denmark, the correlations are even more scattered. Overall, these results imply that there is considerable variation in the timing and magnitude of business cycles across countries.

\section{Evidence on the Interaction between Business Cycles and Seasonal Cycles}

\section{A Measuring the Interaction}

To determine how the excess capacity available during the summer months is used over the course of the business cycle, we need to construct an estimate of the interaction between the business cycle and the seasonal cycle. In order to estimate $\mathrm{Q}_{\mathrm{s} \lambda}$, we begin by recognizing that the first-order conditions from the firms' cost minimization problem imply that output is implicitly defined as a function of the season and the state of the business 
Table 3: Descriptive Statistics For Band-Pass Filtered Estimates of Country-Specific Business Cycles

\begin{tabular}{|c|c|c|c|c|c|c|}
\hline \multirow[t]{2}{*}{ Country } & \multirow{2}{*}{$\begin{array}{l}\text { Standard Deviation } \\
\text { of Business Cycle } \\
\text { Proxy }\end{array}$} & \multicolumn{5}{|c|}{$\begin{array}{c}\text { Cross-Correlation of } \\
\text { Specific Proxy at lead } t+k \\
\text { with OECD Business Cycle Proxy at } t\end{array}$} \\
\hline & & $\mathrm{k}=+12$ & $\mathrm{k}=+6$ & $\mathrm{k}=0$ & $\mathrm{k}=-6$ & $\mathrm{k}=-12$ \\
\hline OECD Total & 0.027 & 0.32 & 0.79 & 1.00 & $0.7 \overline{9}$ & 0.32 \\
\hline Austria & 0.035 & -0.13 & 0.37 & 0.71 & 0.67 & 0.34 \\
\hline Belgium & 0.026 & 0.21 & 0.59 & 0.84 & 0.62 & 0.18 \\
\hline Canada & 0.044 & 0.25 & 0.72 & 0.78 & 0.51 & 0.17 \\
\hline Denmark & 0.024 & -0.00 & 0.18 & 0.46 & 0.48 & 0.22 \\
\hline Finland & 0.029 & -0.14 & 0.19 & 0.41 & 0.50 & 0.46 \\
\hline France & 0.025 & 0.21 & 0.60 & 0.84 & 0.61 & 0.13 \\
\hline Germany & 0.026 & -0.04 & 0.49 & 0.78 & 0.72 & 0.48 \\
\hline Greece & 0.020 & 0.02 & 0.49 & 0.67 & 0.50 & 0.24 \\
\hline Ireland & 0.030 & 0.36 & 0.77 & 0.85 & 0.52 & 0.08 \\
\hline Italy & 0.034 & 0.02 & 0.46 & 0.78 & 0.65 & 0.20 \\
\hline Japan & 0.036 & 0.16 & 0.66 & 0.89 & 0.77 & 0.39 \\
\hline Luxembourg & 0.050 & 0.23 & 0.58 & 0.85 & 0.73 & 0.33 \\
\hline Netherlands & 0.022 & -0.05 & 0.50 & 0.83 & 0.70 & 0.36 \\
\hline Norway & 0.017 & -0.35 & -0.14 & 0.19 & 0.42 & 0.35 \\
\hline Portugal & 0.027 & 0.21 & 0.21 & 0.35 & 0.48 & 0.53 \\
\hline Spain & 0.019 & 0.56 & 0.65 & 0.69 & 0.49 & 0.20 \\
\hline Sweden & 0.027 & -0.08 & 0.17 & 0.31 & 0.31 & 0.16 \\
\hline U.K. & 0.031 & 0.54 & 0.65 & 0.73 & 0.54 & 0.10 \\
\hline U.S. & 0.036 & 0.45 & 0.83 & 0.90 & 0.60 & 0.15 \\
\hline
\end{tabular}

The business cycle proxies are obtained by applying Baxter and King's (1995) band-pass-filtering algorithm to the logarithm of not-seasonally-adjusted total manufacturing production indices obtained from the OECD. The filter removes all fluctuations of frequency lower than eight years and higher than eighteen months. 
cycle. Writing this as $\mathrm{Q}=\mathrm{Q}(\mathrm{S}, \lambda)$ and taking a second-order Taylor series approximation about $\bar{Q}=Q(\bar{S}, \bar{\lambda})$, yields

$$
\begin{gathered}
Q-\bar{Q}=Q_{s}(S-\bar{S})+Q_{\lambda}(\lambda-\bar{\lambda})+Q_{\lambda s}(S-\bar{S})(\lambda-\bar{\lambda}) \\
+1 / 2 Q_{s s}(S-\bar{S})^{2}+1 / 2 Q_{\lambda}(\lambda-\bar{\lambda})^{2}
\end{gathered}
$$

Since we will define $S$ as a dummy variable indicating the month of the year, $S=S^{2}$, and we can, without loss of generality, set $Q_{S s}$ to zero. Strictly speaking, equation (8) describes the dynamics for the level of production. However, to maintain comparability with previous work, we will do the empirical work using the logarithm of production. Thus, we blur the distinction between levels and logs and study the logarithmic (rather than arithmetic) difference between $Q-\bar{Q}$.

Allowing for the possibility that $\ln \overline{\mathrm{Q}}$ contains both a deterministic time trend and a random non-stationary component, leads us to consider:

$$
\mathrm{q}_{\mathrm{t}}=\alpha \mathrm{t}+\sum_{\mathrm{i}=1}^{12} \sigma_{\mathrm{i}} \mathrm{s}_{\mathrm{i}, \mathrm{t}}+\sum_{\mathrm{i}=1}^{12} \rho_{\mathrm{i}} \mathrm{s}_{\mathrm{i}, \mathrm{t}} \lambda_{\mathrm{t}}+\delta \lambda_{\mathrm{t}}^{2}+\varepsilon_{\mathrm{t}}
$$

where $q_{t}$ is the $\log$ of production, $s_{i, t}$ is a dummy variable that is equal to 1 in season $i, \lambda_{t}$ is a measure of the business cycle and $\varepsilon_{t}$ is the random element of $\ln \bar{Q}_{t}$. Since we include a dummy variable for each month, we omit both a constant and a term for the level of $\lambda$ in (9). These terms can be inferred from the average values of the $\sigma_{i}^{\prime}$ 's and $\rho_{i}$ 's respectively. To handle the potential non-stationarity of $\varepsilon$, we estimate a differenced version of equation (9). To facilitate this, it is convenient to renormalize the seasonal dummies so that seasons are all defined relative to the average (i.e. let $S_{i, t}=s_{i, t}-s_{12, t}$ and $S_{12, t}=\sum_{i=1}^{12} s_{i, t}$ ). Therefore, 
the transformed version of (9) which we estimate is:

$$
\begin{gathered}
\Delta \mathrm{q}_{\mathrm{t}}=\alpha+\sum_{\mathrm{i}=1}^{11} \beta_{\mathrm{i}}\left(\mathrm{S}_{\mathrm{it}}-\mathrm{S}_{\mathrm{it}-1}\right)+\sum_{\mathrm{i}=1}^{11} \phi_{\mathrm{i}}\left(\lambda_{\mathrm{t}} \mathrm{S}_{\mathrm{it}}-\lambda_{\mathrm{t}-1} \mathrm{~S}_{\mathrm{it}-\mathrm{l}}\right) \\
\quad-\bar{\rho} \Delta \lambda_{\mathrm{t}}+\delta \Delta \lambda_{\mathrm{t}}^{2}+\Delta \tilde{\varepsilon}_{\mathrm{t}},
\end{gathered}
$$

where $\beta_{\mathrm{i}}$ and $\phi_{\mathrm{i}}$ are deviations from average seasonal effects, $\alpha=\alpha+E_{0}\left(\Delta \varepsilon_{1}\right), \Delta \tilde{\varepsilon}_{\mathrm{t}}=\Delta \varepsilon_{\mathrm{t}}-$ $\mathrm{E}_{0}\left(\Delta \varepsilon_{\mathrm{t}}\right)$ and $\mathrm{E}_{0}\left(\Delta \varepsilon_{\mathrm{t}}\right)$ is the drift in $\varepsilon_{\mathrm{t}}$.

The natural measure of whether seasonal cycle and business cycle are related is the quantity:

$$
V(\lambda)=\sum_{i=1}^{12}\left(\beta_{i}+\phi_{i} \lambda\right)^{2}
$$

This is the variance of the estimated seasonal effects. Computing an estimate of $\mathrm{V}$ for different levels of $\lambda$ allows us to quantify the impact of cyclical movements on the size of seasonal fluctuations. To summarize these interactions, we follow, Cecchetti, Kashyap and Wilcox (1995) and examine the statistic:

$$
\mathbf{R}\left(\lambda^{1}, \lambda^{h}\right) \equiv \mathrm{V}\left(\lambda=\lambda^{\mathrm{h}}\right) / \mathrm{V}\left(\lambda=\lambda^{\mathrm{l}}\right)
$$

where $\lambda^{h}$ and $\lambda^{l}$ are values of $\lambda$ that obtain near a business cycle peaks and troughs respectively. Thus, a finding that $\mathbb{R}$ is less than 1 indicates that the estimated seasonal cycle is trimmed during a business cycle boom relative to a business cycle bust.

\section{B Estimation Results}

Table 4 reports our estimated values of $\mathbf{R}$ when $\lambda^{\mathrm{h}}$ is set equal to the mean of the top $15 \%$ of the values for the business cycle proxy (i.e. the $85-100 \%$ of $\lambda$ ) and $\lambda^{\prime}$ is set equal to 
Table 4: Estimated Cyclical Changes in Seasonal Variation

\begin{tabular}{|c|c|c|c|c|c|c|c|c|c|c|c|c|c|c|c|}
\hline \multirow[b]{2}{*}{ Country } & \multirow[b]{2}{*}{ Food } & \multirow[b]{2}{*}{ Textiles } & \multirow[b]{2}{*}{ Wood } & \multirow[b]{2}{*}{ Paper } & \multirow[b]{2}{*}{ Chemicals } & \multirow{2}{*}{$\begin{array}{l}\text { Non-Metal. } \\
\text { Min. Prod. }\end{array}$} & \multirow{2}{*}{$\begin{array}{l}\text { Basic } \\
\text { Metals }\end{array}$} & \multirow{2}{*}{$\begin{array}{l}\text { Metal } \\
\text { Prod. }\end{array}$} & \multirow{2}{*}{$\begin{array}{l}\text { NonElec. } \\
\text { Mach. }\end{array}$} & \multirow{2}{*}{$\begin{array}{l}\text { Elec. } \\
\text { Mach. }\end{array}$} & \multirow{2}{*}{$\begin{array}{l}\text { Trans. } \\
\text { Equip. }\end{array}$} & \multicolumn{4}{|c|}{ Total Number } \\
\hline & & & & & & & & & & & & $R \geq 1$ & $R<1$ & $p \leq 0.05$ & $p \leq 0.10$ \\
\hline Austria & 0.63 & 0.98 & 0.87 & 0.75 & 0.96 & 0.91 & 1.06 & 1.47 & 0.76 & 1.08 & 0.95 & 3 & 8 & 1 & 1 \\
\hline Belgium & 1.13 & 1.02 & 1.32 & 0.76 & 0.93 & 0.63 & 0.63 & 1.34 & 1.21 & 2.06 & 1.33 & 7 & 4 & 2 & 3 \\
\hline Canada & 0.75 & 1.10 & 1.09 & 0.87 & 1.10 & 0.98 & 0.68 & 1.09 & 1.08 & 0.82 & 0.85 & 5 & 6 & 1 & 1 \\
\hline Denmark & 0.47 & 0.80 & 0.81 & 0.72 & 0.90 & 1.03 & 0.59 & 0.87 & 0.64 & 0.70 & 1.04 & 2 & 9 & 4 & 5 \\
\hline Finland & 1.07 & 0.93 & 0.69 & 0.13 & 0.39 & 0.71 & 0.46 & 0.71 & 0.73 & 0.64 & 1.15 & 2 & 9 & 3 & 5 \\
\hline France & 0.67 & 1.00 & 0.32 & 0.21 & 0.82 & 0.60 & 0.99 & 0.54 & 0.15 & 0.74 & 1.00 & 1 & 10 & 5 & 5 \\
\hline Germany & 1.09 & 0.85 & 0.83 & 0.79 & 0.98 & 0.92 & 0.84 & 0.59 & 1.13 & 0.67 & 0.91 & 2 & 9 & 2 & 2 \\
\hline Greece & 0.76 & 0.84 & 0.89 & 0.87 & 0.66 & 0.45 & 0.59 & 0.78 & 0.74 & 0.48 & 1.64 & 1 & 10 & 1 & 1 \\
\hline Ireland & 1.39 & 1.03 & 0.98 & 1.14 & 0.93 & 0.60 & 0.51 & 0.84 & 1.13 & 1.52 & 0.70 & 5 & 6 & 1 & 2 \\
\hline Italy & 1.21 & 1.01 & 0.90 & 0.90 & 1.03 & 0.98 & 1.13 & 0.97 & 0.77 & 0.99 & 0.80 & 4 & 7 & 0 & 1 \\
\hline Japan & 0.60 & 1.09 & 0.92 & 0.69 & 1.36 & 0.86 & 0.83 & 0.57 & 1.12 & 0.80 & 0.97 & 3 & 8 & 4 & 5 \\
\hline Luxembourg & 1.27 & 0.41 & 1.11 & 1.74 & 1.14 & 1.11 & 0.29 & 0.45 & 0.87 & 0.78 & 1.13 & 6 & 5 & 2 & 3 \\
\hline Netherlands & 1.03 & 0.94 & 1.20 & 1.10 & 0.59 & 1.56 & 0.47 & 1.19 & 0.43 & 0.79 & 0.94 & 5 & 6 & 1 & 1 \\
\hline Norway & 0.60 & 0.80 & 0.93 & 0.59 & 0.66 & 0.76 & 0.14 & 0.73 & 0.98 & 0.80 & 0.68 & 0 & 11 & 6 & 7 \\
\hline Portugal & 0.63 & 1.16 & 2.73 & 0.46 & 1.04 & 0.47 & 1.09 & 0.48 & 0.74 & 1.51 & 0.75 & 5 & 6 & 1 & 2 \\
\hline Spain & 1.27 & 1.21 & 1.00 & 0.93 & 0.83 & 1.20 & 0.71 & 0.76 & 0.70 & 1.03 & 1.29 & 5 & 6 & 0 & 0 \\
\hline Sweden & 0.93 & 0.68 & 0.77 & 0.49 & 0.98 & 0.65 & 0.90 & 1.01 & 0.82 & 1.15 & 0.80 & 2 & 9 & 1 & 2 \\
\hline U.K. & 1.00 & 0.94 & 0.92 & 1.06 & 0.73 & 0.87 & 0.76 & 0.65 & 1.29 & 0.93 & 1.12 & 3 & 8 & 1 & 2 \\
\hline U.S. & 1.23 & 0.62 & 0.61 & 1.61 & 1.40 & 2.33 & 1.93 & 0.89 & 1.75 & 1.61 & 2.72 & 8 & 3 & 3 & 6 \\
\hline & \multicolumn{11}{|c|}{ Total Number } & & & & \\
\hline$R \geq 1$ & 10 & 8 & 6 & 5 & 6 & 5 & 4 & 5 & 7 & 7 & 9 & & & & \\
\hline$R<1$ & 9 & 11 & 13 & 14 & 13 & 14 & 15 & 14 & 12 & 12 & 10 & & & & \\
\hline$p \leq 0.05$ & 5 & 1 & 4 & 4 & 1 & 6 & 4 & 5 & 2 & 6 & 1 & & & & \\
\hline$p \leq 0.10$ & 5 & 2 & 7 & 7 & 2 & 6 & 5 & 8 & 4 & 6 & 2 & & & & \\
\hline
\end{tabular}

Raw numbers are ratio of the variance of the production seasonal in a boom relative to that in a recession. Bold-faced numbers are different from one at the five-percent level, while those in italics are different from one at the ten-percent level. The final four rows and columns report summary measures related to several questions of interest. Hypothesis test results are based on standard errors computed using the Newey and West (1987) covariance matrix estimator with 24 lags. 
the mean of the bottom $15 \%$ of the values of the business cycles proxy. Since we have data on 19 countries, and 11 industries, the table reports 209 estimated values of $\mathbb{R}$. The mean estimated value of $\mathbb{R}$ is .92 , and roughly two-thirds of the point estimates of the countryindustry pairs (137/209) are less than one which implies that seasonal cycles are trimmed during a boom.

The estimated $\mathbb{R}$ 's which are significantly different from 1 at the 5 percent level of significance are shown in bold. ${ }^{13}$ Among the 39 statistically significant estimates, 34 suggest that $\mathbb{R}^{\prime}$ s are significantly below 1 and 5 are significantly larger than 1 . Using the 10 percent level of significance as the critical value implies that 15 more estimates are different from 1. These estimates are shown in italics in the table and using this standard, 43 of 209 total entries are significantly less than 1.0. Thus, there is weak evidence in favor of the view that some of the excess capacity in the summer is used to avoid additional production bunching in the high output seasons during business cycle booms.

So far, we have ignored the fact that the $\mathbb{R}$ 's have common industry and country components. This suggests that we can improve the precision of our inferences by pooling the data. We, therefore, consider the following regression:

$$
\mathbb{R}_{i, j}=a_{i} I_{i}+b_{j} I_{j}+e_{i, j}
$$

where $I_{i}$ is an indicator variable which is equal to 1 for industry $i$ and 0 otherwise, and $I_{j}$ is an indicator variable which is equal to 1 for country $\mathrm{j}$ and 0 otherwise and $\mathrm{e}_{\mathrm{i}, \mathrm{j}}$ is the unexplained portion of $\mathbb{R}$.

${ }^{13}$ Standard error estimates are based on Newey and West (1987) covariance-matrix estimates with 24 lags. 
Since we can estimate the variance of $\mathbb{R}_{\mathrm{i}, \mathrm{j}}$ at the same time that we obtain its point estimate, we can improve the precision of our estimated industry and country effects by using a weighted least squares estimation procedure. The results we report are calculated after normalizing each observation by its production share of total OECD output and assuming the variance of $e_{i, j}$ is proportional to the estimated variance of the $\mathbb{R}_{i, j}$-- although it turns out that the qualitative results are not terribly sensitive to the weighting scheme. For instance, the unweighted regression estimates have the same properties that we emphasize below, albeit with larger standard errors.

Finally, because the regression does not include a constant, the estimated $a_{i}$ 's provide a measure of the size of the shrinkage of the seasonal cycle in each industry, and because we restrict the coefficients on country dummies to sum to zero, the estimated $b_{j}$ 's measure the extent to which the seasonal that is common to all industries in a country moves during a boom.

The results from estimating (13) are shown in table 5. We draw four main conclusions from the estimates. First, by pooling the data we have recovered much more precise estimates of the industry and country effects. Second, we find that, except for the textiles industry and to a lesser extent the transportation equipment and chemicals industries, the seasonal cycle in production is significantly less volatile during a business cycle boom than during a business cycle contraction --i.e. the estimated $a_{i}$ 's are almost always significantly less than 1 . Third, we find that there are significant cyclical/seasonal interactions that are common to all industries in a given country for about a third of the countries -- i.e., 6 out of 19 estimated $b_{j}$ 's are significantly different from zero at the five- 
Table 5: Estimates of Country and Industry Fixed Effects in Cyclical Changes in Scasonal Variation

\begin{tabular}{||l|c|c||}
\hline \hline Industry & Mean & p-value $H_{o}: \beta=1$ \\
\hline Food & 0.781 & 0.01 \\
Textiles & 0.961 & 0.76 \\
Wood and Wood Products & 0.642 & 0.00 \\
Paper, Printing and Pub. & 0.747 & 0.00 \\
Chemicals & 0.903 & 0.15 \\
Non-Metallic Mineral Prod. & 0.866 & 0.00 \\
Basic Metals & 0.767 & 0.01 \\
Metal Products & 0.768 & 0.00 \\
Nonclectrical Machinery & 0.645 & 0.00 \\
Electrical Machinery & 0.801 & 0.00 \\
Transportation Equipment & 0.895 & 0.14 \\
\hline & Deviation & $\mathrm{p}$-value \\
Country & from Mean & for $H_{o}: \beta=0$ \\
\hline Austria & 0.124 & 0.11 \\
Belgium & 0.106 & 0.18 \\
Canada & 0.060 & 0.38 \\
Denmark & -0.040 & 0.38 \\
Finland & -0.195 & 0.19 \\
France & -0.333 & 0.00 \\
Germany & 0.051 & 0.50 \\
Greece & -0.208 & 0.00 \\
Ireland & 0.174 & 0.15 \\
Italy & 0.121 & 0.00 \\
Japan & 0.019 & 0.78 \\
Luxcmbourg & -0.374 & 0.00 \\
Netherlands & 0.145 & 0.16 \\
Norway & -0.205 & 0.02 \\
Portugal & 0.065 & 0.56 \\
Spain & 0.117 & 0.03 \\
Sweden & 0.063 & 0.44 \\
U.K. & 0.069 & 0.32 \\
U.S. & 0.239 & 0.11 \\
\hline Grand Mean & 0.798 & 0.00 \\
\hline St. Dev. of Industry Effects $=0.102$ & \\
St. Dev. of Country Effects $=0.176$ & \\
\hline \hline & & \\
\hline
\end{tabular}

Results from weight-least-squares regression of the 209 estimated $\mathcal{R}$ 's in Table 4 on industry and country fixed effects, without a constant, weighted by the ratio of the estimated variance of $\hat{\mathcal{R}}_{i j}$ (computed using Newey-West with 24 lags) to the share of industry $i$, in country $j$, relative to total OECD production. The country-specific fixed effects are constrained to sum to zcro. The 'Grand Mean,' as well as the standard deviation of the country and industry effects are calculated from a weight-least-squares regression where both the industry- and country-specific fixed effects are constrained to sum to zero. Hypothesis test results are based on standard errors that are robust to heteroskedasticity. 
percent level of significance. Finally, the standard deviation of the country estimates is about $70 \%$ larger than the standard deviation of the estimated industry effects. ${ }^{14}$ Thus, in relative terms, the estimated interactions that are common to countries are larger than the interactions that are common to industry.

\section{C Economic Significance}

To this point, we have avoided any discussion of the economic significance of the interactions. To draw any conclusions about the importance of the estimated changes in seasonality that occur over the course of the business cycle, one must develop a metric for deciding how to normalize the changes. In most countries, the seasonal shifts are dominated by a summer slowdown. This leads us to approximate the seasonal pattern as arising purely from a one month shutdown/vacation. In other words, we adopt a simplification in which the seasonal pattern is assumed to have 11 equal months and one month with a large drop. The resulting seasonal regression coefficients are then proportional to a vector with 11 ones and one -11 -- i.e., $(1,1,1,1,1,1,1,-11,1,1,1,1)$. When this is the case, the variance of the seasonal coefficients is totally dominated by the size of the drop and recovery that arise from the vacation. Thus, we can use alternative estimates of $V(\lambda)$ defined in (11) to infer the change in the size of the vacation that comes from the interaction between the business cycle and the seasonal cycle.

For example, we can take a given industry in a given country, say the paper industry in France, and use equation (11) to construct an estimate of the variance of the seasonal

\footnotetext{
${ }^{14}$ These same basic patterns also show up when the regression is separately for G7 countries and non-G7 countries, although the country effects are only 15 to $40 \%$ larger than the industry effects once the sample is stratified in this way.
} 
coefficients in a boom. We can then compute the size of the vacation effect that is required to rationalize this variance estimate. The same calculation can be repeated to get an estimated size of the vacation in the French, paper industry during an economy-wide recession. Comparing the two estimates provides an indication of the amount of production that is reallocated from high production months to low production months during a boom. Of course, we can do these calculations for all country-industry pairs. In addition, we can compute the average size of the vacation effect in each industry and country from the results in Table 5 .

Table 6 shows how much the vacation seasonal changes for every industry-country pair. Because the seasonal regression coefficients underlying the entries in the table come from equation (10), the units in the table are in terms of the average production for a typical month. Thus, the average estimate for Norway of 0.11 implies that eleven percent of an average month's production is moved from high output months to the low output month as the economy goes from a business cycle trough to a peak.

Once again the average country-specific effects are much larger than the industryspecific effects, although there is considerable heterogeneity in the size of the shifts. We read the evidence as saying that in most cases the shifts involve no more than a couple of days worth of production being reallocated, but in roughly 10 percent of the cases at least one fifth of a month's worth of output is shifted. Given the extrapolation that occurs using standard seasonal adjustment techniques, this sort of reallocation would cause significant changes in one's estimate of the strength of an expansion.

Clearly, these conclusions rest heavily on the assumption of a uniform production 
Table 6: Implied Change in the Size of the Vacation Seasonal from a Boom

\begin{tabular}{|c|c|c|c|c|c|c|c|c|c|c|c|c|}
\hline Country & $\begin{array}{l}\text { Country } \\
\text { Average }\end{array}$ & Food & Textiles & Wood & Paper & Chemicals & $\begin{array}{l}\text { Non-Metal. } \\
\text { Min. Prod. }\end{array}$ & $\begin{array}{c}\text { Basic } \\
\text { Metals }\end{array}$ & $\begin{array}{l}\text { Metal } \\
\text { Prod. }\end{array}$ & $\begin{array}{c}\text { NonElec. } \\
\text { Mach. }\end{array}$ & $\begin{array}{l}\text { Elec. } \\
\text { Mach. }\end{array}$ & $\begin{array}{l}\text { Trans. } \\
\text { Equip. }\end{array}$ \\
\hline Austria & -0.01 & 0.05 & 0.00 & 0.03 & 0.01 & 0.00 & 0.03 & -0.01 & -0.06 & 0.08 & -0.02 & 0.01 \\
\hline Belgium & -0.01 & -0.02 & -0.01 & -0.09 & 0.06 & 0.01 & 0.12 & 0.08 & -0.05 & -0.03 & -0.16 & -0.06 \\
\hline Canada & 0.01 & 0.04 & -0.02 & -0.01 & 0.01 & -0.01 & 0.01 & 0.05 & -0.01 & -0.01 & 0.03 & 0.04 \\
\hline Denmark & 0.07 & 0.08 & 0.09 & 0.09 & 0.06 & 0.02 & -0.01 & 0.26 & 0.04 & 0.14 & 0.14 & -0.01 \\
\hline Finland & 0.04 & -0.01 & 0.05 & 0.18 & 0.24 & 0.19 & 0.11 & 0.25 & 0.15 & 0.13 & 0.24 & -0.07 \\
\hline France & 0.04 & 0.03 & -0.00 & 0.45 & 0.37 & 0.03 & 0.13 & 0.00 & 0.23 & 0.98 & 0.02 & 0.00 \\
\hline Germany & 0.01 & -0.01 & 0.03 & 0.03 & 0.02 & 0.00 & 0.02 & 0.02 & 0.05 & -0.02 & 0.06 & 0.02 \\
\hline Greece & 0.07 & 0.13 & 0.05 & 0.04 & 0.02 & 0.07 & 0.10 & 0.07 & 0.05 & 0.07 & 0.27 & -0.08 \\
\hline Ireland & -0.01 & -0.05 & -0.01 & 0.00 & -0.01 & 0.02 & 0.10 & 0.14 & 0.03 & -0.03 & -0.06 & 0.04 \\
\hline Italy & 0.01 & -0.04 & -0.01 & 0.06 & 0.03 & -0.01 & 0.01 & -0.05 & 0.02 & 0.12 & 0.00 & 0.14 \\
\hline Japan & 0.01 & 0.09 & -0.01 & 0.01 & 0.02 & -0.01 & 0.01 & 0.01 & 0.05 & -0.01 & 0.02 & 0.00 \\
\hline Luxembourg & 0.09 & -0.03 & 0.24 & -0.03 & -0.09 & -0.03 & -0.03 & 0.25 & 0.19 & 0.03 & 0.13 & -0.04 \\
\hline Netherlands & -0.00 & -0.00 & 0.02 & -0.04 & -0.01 & 0.04 & -0.10 & 0.08 & -0.03 & 0.16 & 0.05 & 0.01 \\
\hline Norway & 0.11 & 0.11 & 0.12 & 0.03 & 0.12 & 0.09 & 0.07 & 0.20 & 0.13 & 0.01 & 0.13 & 0.13 \\
\hline Portugal & 0.00 & 0.07 & -0.07 & -0.55 & 0.12 & -0.01 & 0.06 & -0.02 & 0.28 & 0.14 & -0.21 & 0.12 \\
\hline Spain & 0.00 & -0.03 & -0.06 & 0.00 & 0.01 & 0.05 & -0.02 & 0.08 & 0.14 & 0.20 & -0.02 & -0.21 \\
\hline Sweden & 0.05 & 0.01 & 0.28 & 0.20 & 0.16 & 0.01 & 0.20 & 0.07 & -0.01 & 0.11 & -0.08 & 0.16 \\
\hline U.K. & 0.01 & 0.00 & 0.01 & 0.01 & -0.01 & 0.03 & 0.02 & 0.05 & 0.05 & -0.04 & 0.01 & -0.01 \\
\hline U.S. & -0.02 & -0.02 & 0.04 & 0.02 & -0.02 & -0.01 & -0.13 & -0.07 & 0.01 & -0.06 & -0.04 & -0.15 \\
\hline Industry Ave. & 0.03 & 0.03 & 0.03 & 0.05 & 0.03 & 0.03 & 0.02 & 0.02 & 0.05 & 0.01 & 0.03 & -0.01 \\
\hline
\end{tabular}

The table reports the change in the size of the vacation seasonal, assuming that production seasonals are proportional to $(1,1,1,1,1,1,1,-11,1,1,1,1)$. Units are the $\log$ of one-month's average production. The values in the first column and last row are fixed-effects estimates constructed using the same methods described in Table 5. We estimate equation a weighted-least-squares regression of the 209 estimated values in the main part of the Table, withou a constant, weighted by the ratio of the estimated variance of the vacation effect in each country/industry pair(computed using Newey-West with 24 lags) to the share of industry $i$, in country $j$, relative to total OECD production. The remaining estimates are based on direct calculation of the variance of production during a boom and a recession - the numerator and denominator of the numbers reported in Table 4. 
pattern and a single drop. However, one can show that this assumed seasonal pattern leads to an intermediate estimate regarding the size of the seasonal reallocation that takes place. The largest reallocation occurs when the seasonal pattern is a sequence of alternating expansions and contractions of equal size. Conversely, if the seasonal pattern were 10 months of constant production and one high season with one off-setting low season one can show that we get a much smaller estimate of the reallocation. Thus, although our interpretation does depend on the specific assumption we have made we think that our assumed pattern is plausible and it is clear that the results are not biased towards demonstrating large effects.

\section{D Robustness}

All of our estimates thus far rely on the use of a country specific business cycle indicator. But our simple theory suggests that industry level capacity constraints (within a country) should be the cause of any interactions between seasonal cycles and business cycles. One possibility is to use a cyclical proxy constructed from OECD total output for each industry -- $\bar{\lambda}_{\mathrm{i}}$ instead of $\bar{\lambda}_{\mathrm{j}}$. But constructing the cyclical proxy using only industry-specific information runs into the obvious problem that total OECD industry-wide output is necessarily correlated with industry output from each country. While we are comfortable assuming that our measures of $\lambda$ derived from total manufacturing output are plausibly exogenous at the industry level, we would not make the same claim for estimates of $\lambda$ constructed using only industry-wide information.

Nevertheless, we are able to check how our results might differ if some industry-level data were used in constructing the cyclical proxy by doing the following experiment. We applied the Baxter-King band pass filter to total worldwide industry output to get a cyclical 
proxy for each industry $\left(\bar{\lambda}_{\mathrm{i}}\right)$. We then used our country-specific measures of the business cycle as instruments for these industry specific measures and re-estimated equation (10). The results of the fixed effects regressions analogous to Table 5 are very similar. Production in all eleven industries show less seasonality during business cycle booms (and the shrinkages were significant at the five percent level in all but one case). The variation in the estimated country effects continues to be somewhat larger than the estimated industry effects -- now by 20\%. Thus, our key qualitative conclusions are robust to using some industry specific information in identifying the business cycle.

\section{E Interpretation}

We now return to the question of what the results imply about the shape of firms' cost curves. If we maintain the assumption that the inventory holding cost function is linear, then the results from Table 5 imply that firms' marginal cost curves have statistically significant positive third derivatives for eight of our eleven industries. In this case, we can interpret the country coefficients as a measure of the degree to which the curvature arises from the synchronized cost movements within a country.

Because many of the country effects are brought on by the large summer slowdowns, this identification scheme is consistent with interpreting these shifts as movements in labor supply. Furthermore, the relative magnitude of the coefficient estimates suggests that these labor supply swings are more important than the typical industry specific factors that might give rise to capacity constraints.

Of course, there are other things, besides preferences for vacations that could be responsible for the country effects. For instance, differences in weather patterns across 
countries might suggest that the sky-rocketing cost of air-conditioning a plant is responsible for the summer slowdowns in some regions. But, given the strong differences between adjacent countries (e.g. Luxembourg and Belgium) we are doubtful that the country-specific effects can be easily explained by differences in weather. Another possibility is that differences in labor contracts, union work rules and tax rates make intertemporal adjustments more or less costly.

This observation leads us to examine the correlation between cross-country patterns and various measures of taxation and labor market structure. Because of the difficulties in finding comparable data for so many countries, it is not possible to obtain precise estimates of many of the variables we might like to study. However, Summers, Gruber and Vergara (1993) assembled data (which are described in their Data Appendix) for fourteen of the countries in our sample -- they do not report information for Greece, Ireland, Luxembourg, Portugal and Spain. Their study includes measures of corporatism (defined as "a mode of social organization in which functional groups rather than discrete individuals wield power and transact affairs" and measured by the Calmors-Drifill Index), union density, and the political power of workers (the Cameron Leftist Index). These variables can be viewed as crude indicators of the degree to which firms would have the political power to reorganize workers' schedules. Summers, Gruber and Vergara also report data on marginal tax rates for labor income, equipment and structures. These are proxies for the costs of adjusting workers instead of capital.

Table 7 reports the results of regressing the country fixed effects from Table 5 on each of the measures individually and then all at once. The first column shows that 
Table 7: Correlation of Country Effects with Measures of Taxation and Labor Market Structure

\begin{tabular}{||l|c|c||}
\hline \hline Variable & Univariate Regression & Multivariate Regression \\
\hline Calmfors-Drifill & -0.011 & -0.055 \\
Corporatism Index & $(-1.26)$ & $(-2.79)$ \\
\hline Union & -0.128 & 0.300 \\
Density & $(-0.50)$ & $(0.78)$ \\
\hline Cameron Leftist & -0.003 & 0.022 \\
Index & $(-0.36)$ & $(3.13)$ \\
\hline Marginal Labor & -0.003 & 0.007 \\
Income Tax Ratc & $(-1.07)$ & $(1.37)$ \\
\hline Marginal Equipment & -0.001 & -0.005 \\
Tax Rate & $(-1.63)$ & $(-2.56)$ \\
\hline Marginal Structures & $\mathbf{0 . 0 0 1}$ & 0.008 \\
Tax Ratc & $(0.44)$ & $(3.77)$ \\
\hline
\end{tabular}

Results are from the regression of fourteen of the nineteen estimated country fixed-effects reported in Table 5 on variables from Summers, Gruber and Vergara (1993). Asymptotic t-ratios, robust to heteroskedasticity, are in parentheses. 
individually none of the proxies are significant predictors of whether the seasonal cycle grows or shrinks in a given country during a boom. For the only case where a result is borderline significant, we find that in countries with high marginal tax rates on capital equipment (and hence probably higher costs to add capacity) there is more smoothing of seasonals in a boom than a bust.

The second column of Table 7 shows that taking the heroic step of simultaneously include all six measures in a single regression gives a surprisingly plausible set of findings. The three political variables indicate than when a country is more corporatist, less unionized and less leftist, the seasonality in production is more prone to be smoothed over the course of the business cycle. Similarly, if tax rates on labor income or structures (which are presumably complements to labor) are low, or tax rates on capital equipment (which is presumably a substitute for labor) are high, then more smoothing is also predicted. While these results are quite favorable for the labor supply/vacation explanation for the interactions, given the small number of observations underlying the regressions this evidence should be viewed cautiously.

Real confirmation of the vacation hypothesis requires checking some of its additional predictions. For example, if the desire to coordinate vacations among multiple family members is important, then one could see if countries with smaller families have less synchronized slowdowns. We think that this kind of further exploration is important, but it is beyond the scope of our paper.

Our alternative identifying assumptions presume that the country-level seasonalcyclical interactions arise from country-specific demand factors. The results in Table 5 
suggest that these taste shocks would have to be relatively large. There are several ways one could try to separate the cost and demand explanations for the country effects. For instance, demand-based explanations would imply that while production is low, there would be no tendency for consumption to shift towards the purchases of foreign goods. Alternatively, if country-specific cost factors are responsible, then one would expect to see some shifts towards the purchase of imported goods.

Similarly, if inventory data could be obtained, one could try to check directly check whether the linear holding cost assumption for inventories is empirically supported. If the linearity is borne out in the data, we could reject the demand explanation. ${ }^{15}$ We hope that in subsequent work these tests can be conducted.

\section{Conclusions}

Our empirical work gives a unified comparison of the seasonal cycles and business cycles across 19 OECD countries. We are able to confirm a number of previously documented patterns. In particular, we find that a tremendous amount of volatility in production is accounted for by seasonal shifts, but that the seasonal shifts are not very highly correlated across countries. There are also considerable differences in the timing and magnitude of business cycles across countries. Lastly, the country-level differences in seasonality are larger than the industry-level patterns in seasonality.

In addition to these basic observations, we go on to establish a number of new results describing how seasonal production patterns vary over the course of the business cycle. With

${ }^{15}$ This is the strategy pursued in Cecchetti, Kashyap and Wilcox (1995). 
the exception of textiles, and to a lesser extent transportation equipment and chemicals, the seasonal cycle in production is significantly less volatile during a business cycle boom than it is during a business cycle contraction. We also document that for one-third of the nineteen countries in our sample, there are significant cyclical/seasonal interactions common to all of industries within the country. In relative terms, the estimated interactions that are common to countries are larger than the interactions that are common to industries -- this is in line with our finding that the overall variation in production differs more across countries than it does across industries. Finally, the reallocation of production from high output months to low output months that typically occurs in moving from a business cycle trough to peak is sometimes quite large.

We interpret this evidence using a model that shows how demand and cost conditions could lead to seasonal and cyclical interactions. Our preferred version of the model imputes all of the interactions to non-linearities in the marginal cost curve. In this case, the evidence can be read as suggesting that capacity constraints are empirically important.

We see several directions for further work. An important one is to try to distinguish among the many possible explanations for the large element of the seasonal and cyclical interactions that appear to be common to industries and countries. A second possibility is to carefully explore the implications of these findings for standard methods used for seasonal adjustment. 


\section{Data Appendix}

The basic data source is the OECD "Indicators of Industrial Activity" diskettes supplied by the OECD. These diskettes were the source for the manufacturing total industrial production and the industrial production in the eleven industries studied. Table Al gives the data availability for each series. Additional data on aggregate manufacturing industrial production, from 1972 to 1974, were obtained from the OECD's Main Economic Indicators. The one exception is Denmark, where data prior to 1975 was unavailable.

The data were checked by comparing them with data obtained from Data Resources Inc. (DRI). In nearly all cases, the correlation between the series was 0.99 or higher. In those cases were the correlation was below 0.99 , the data were plotted. In virtually all of the cases, the failure of the data to match was the result of a level shift in the raw series, suggesting that one of the series was improperly spliced. In these cases, the data without the level shift was chosen for further analysis. As a result, five disaggregated production series used are from DRI. These are Great Britain ISIC 33 and ISIC 38, Portugal ISIC 33 and ISIC 35 and France ISIC 384.

For the construction of the band-pass filtered series, data on total manufacturing industrial production beginning in 1972:01 was used, where available. With one exception, these data were taken from DRI, and are based on data from the Main Economic Indicators. The series for Denmark is from the OECD Indicators of Industrial Activity. 
Table A1: Data Availability

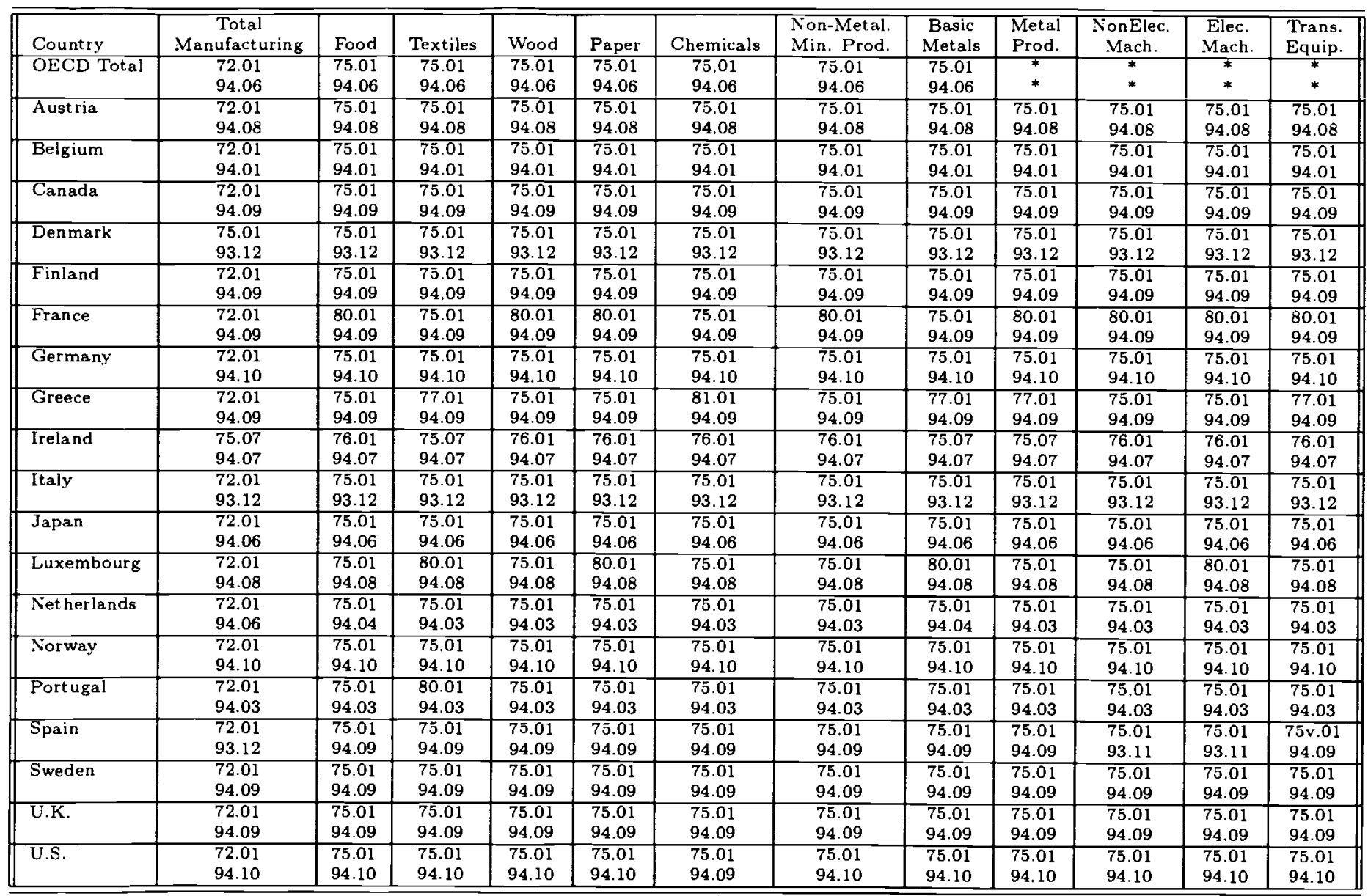

Portugal ISIC 34 is ISIC 3411, Pulp, Paper and Paperboard, no Printing and Publishing. To the extent that it was required, total OECD data for ISIC $381,382,383$ and 384 was constructed from the individual country data using the share weights computed from information in the OECD's Industrial Structure Statistics. 


\section{References}

Backus, David K. and Patrick J. Kehoe. 'International Evidence on the Historical Properties of Business Cycles', American Economic Review, 82, September 1992, pp. 864888.

Baxter, Marianne and Robert G. King, 'Measuring Business Cycles: Approximate Band-Pass Filters for Economic Time Series", NBER Working Paper No. 5022, February 1995.

Beaulieu, J. Joseph, Jeffrey K. MacKie-Mason, and Jeffrey A. Miron, 'Why Do Countries and Industries with Large Seasonal Cycles Also Have Large Business Cycles?', Quarterly Journal of Economics 107, May 1992, 621-656.

Beaulieu, J. Joseph and Jeffrey A. Miron, 'A Cross Country Comparison of Seasonal Cycles and Business Cycles,' Economic Journal, 102, July 1992, 772-788.

Blinder, Alan S. and Louis J. Maccini, 'Taking Stock: A Critical Assessment,' Journal of Economic Perspectives, 5, Winter 1991, pp. 73-96.

Braun, R. Anton and Charles L. Evans, 'Seasonal Solow Residuals and Christmas: A Case for Labor Hoarding and Increasing Returns', mimeo, Federal Reserve Bank of Chicago, 1991.

Burnside, Craig, Martin Eichenbaum and Sergio Rebelo, 'Capital Utilization and Returns to Scale,' in NBER Macroeconomics Annual 1995, Ben S. Bernanke and Julio J. Rotemberg eds., MIT Press, 1995, forthcoming.

Cecchetti, Stephen G., Anil K Kashyap and David W. Wilcox 'Do Firms Smooth the Seasonal in Production in a Boom? Theory and Evidence,' NBER Working Paper No. 5011, February 1995.

Christiano, Lawrence J. and Richard M. Todd, 'The Seasons: Do They Matter for Business Cycle Analysis,' mimeo., Federal Reserve Bank of Minneapolis, March 1995.

Ghysels, Eric 'On Seasonal Asymmetries and Their Implications for Stochastic and Deterministic Models of Seasonality,' mimeo., University of Montreal (1991).

Hansen, Lars Peter and Thomas J. Sargent, 'Seasonality and Approximation Errors in Rational Expectations Models', Journal of Econometrics, 55, pp. 21-56.

Miron, Jeffrey A., 'The Economics of Seasonal Cycles,' NBER Working No. 3388, December 1990. 
Newey, Whitney K. and Kenneth D. West, 'A Simple, Positive Definite, Heteroskedasticity and Autocorrelation Consistent Covariance Matrix,' Econometrica, 55, May 1987, 703-708.

Petersen, Mitchell and Raghuram Rajan, 'The Benefits of Lending Relationships: Evidence from Small-Business Data,' Journal of Finance, 43, January 1994, 3-37.

Rotemberg, Julio J. and Michael Woodford, 'Dynamic General Equilibrium Models with Imperfectly Competitive Product Markets,' N.B.E.R. Working Paper No. 4502, October 1993.

Stockman, Alan C., 'Sectoral and National Disturbances to Industrial Output in Seven European Countries,' Journal of Monetary Economics, 21, March/May 1988, 387-409.

Summers, Lawrence, Jonathan Gruber and Rodrigo Vergara, 'Taxation and the Structure of labor Markets: The Case of Corporatism', Quarterly Journal of Economics, 109 , May 1993, pp. 385-411.

U. S. Department of Commerce, Seasonal Analysis of Economic Time Series, Proceedings of the Conference on the Seasonal Adjustment of Economic Time Series, Washington D. C., Sept. 9-10, 1976, Economic Research Report, ER-1, Arnold Zellner (ed.), 1978, Bureau of the Census, Washington DC 